\title{
IMPACT OF THE SOLUTION COOLING RATE AND OF THERMAL AGING ON THE CREEP PROPERTIES OF THE NEW CAST \& WROUGHT RENÉ 65 Ni-BASED SUPERALLOY
}

\author{
Aude Laurence ${ }^{1,2}$, Jonathan Cormier ${ }^{1}$, Patrick Villechaise ${ }^{1}$, Thomas Billot ${ }^{2}$, Jean- \\ Michel Franchet ${ }^{3}$, Florence Pettinari-Sturmel ${ }^{4}$, Muriel Hantcherli ${ }^{4}$, Frédéric Mompiou ${ }^{4}$, \\ Andrew Wessman 5 \\ ${ }^{1}$ Institut Pprime, UPR CNRS n ${ }^{\circ} 3346$, CNRS - Université de Poitiers - ENSMA, Physics and \\ Mechanics of Materials Department, ISAE-ENSMA, 1 avenue Clément Ader, BP 40109, 86961 \\ Futuroscope - Chasseneuil, France \\ ${ }^{2}$ Snecma-Safran Group, Technical Department, 171 boulevard de Valmy - BP 31, 92702 \\ Colombes Cedex, France \\ ${ }^{3}$ Safran SA, Materials \& Process Division - Research and Technology Center (CRT), 171 \\ boulevard de Valmy - BP 31, 92702 Colombes Cedex, France \\ ${ }^{4}$ CEMES, UPR CNRS n ${ }^{\circ} 8011,29$ rue Jeanne Marvig - BP 94347, 31055 Toulouse Cedex 4, \\ France \\ ${ }^{5}$ GE Aviation, Structural Materials Development, One Neumann Way, Cincinnati, OH 45215- \\ 1988, USA
}

Keywords: thermal overaging, creep, $\gamma^{\prime}$ growth, TCP precipitation

\begin{abstract}
Aeroengines turbine disks can encounter temperature in excess of $700^{\circ} \mathrm{C}-750^{\circ} \mathrm{C}$ for hundreds to thousands of hours in the rim sections during service operations, exposures which may affect the viscoplastic properties of the alloys due to strengthening particles' growth.

The present work aims at quantifying and analyzing the impact of $\gamma^{\prime}$-size evolutions and of intermetallic grain-boundary precipitation during long-term thermal exposures at $700^{\circ} \mathrm{C}$ and $800^{\circ} \mathrm{C}$ on the creep properties at $700^{\circ} \mathrm{C}$ of the newly developed René 65 alloy. In an aim to separate both effects, various sub-solvus solution heat treatments with different cooling rates were used to achieve $\gamma^{\prime}$ sizes comparable to a given thermal exposure in the $700-800^{\circ} \mathrm{C}$ range, without the precipitation of secondary intermetallic particles at grain boundaries. Using this methodology, it is shown unambiguously that the precipitation of TCP phases at grain boundaries is deleterious to the creep properties at $700^{\circ} \mathrm{C} / 800 \mathrm{MPa}$.
\end{abstract}

\section{Introduction}

The development of new generation of civil aeroengines with reduced specific fuel consumption, better efficiency and reduced NOx emissions requires higher operating temperatures. As a consequence, the use of more heat-resistant materials in several sections of gas turbines becomes mandatory (e.g. the plugs in the exhaust parts of new LEAP engines will now be manufactured using alloy $625 \mathrm{Ni}$-based alloy instead of Ti-based alloys [1]). Another issue linked to this increase in operating temperature is the long-term stability of the alloys, and the consequences of the microstructure degradation during service operations on the mechanical properties. In this context, the cast and wrought $(\mathrm{C} \& \mathrm{~W})$ Ni-based superalloy Rene $65^{\mathrm{TM}}$ has recently been developed jointly by ATI Allvac and General Electric as a candidate for the manufacture of low pressure turbine disks in LEAP aeroengines in replacement of the widely used alloy 718 when 
temperatures are too hot. This alloy, which is a derivative of the powder metallurgy René 88DT alloy [2], is solely strengthened by a quite high volume fraction $(\sim 40 \%)$ of $\gamma^{\prime}$ particles. Thanks to a better thermal stability of $\gamma^{\prime}$ particles compared to the $\gamma^{\prime \prime}$ phase one, René 65 (denoted as R65 in the rest of the article) exhibits a higher temperature capability compared to alloy 718 (temperature capability considered to be in the $650-680^{\circ} \mathrm{C}$ temperature range for the latter).

However, as R65 is a recently developed superalloy, its mechanical properties in the $700-800^{\circ} \mathrm{C}$ temperature range as well as its in-service durability have to be characterized to achieve both a better prediction of the components durability and a more efficient design. Indeed, the two main microstructural evolutions likely to occur during in-service high temperature exposures of such an alloy are the growth of the intragranular strengthening $\gamma^{\prime}$ particles and the possible precipitation of intermetallic topologically closed-packed (TCP) phases due to rather high contents of refractory elements such as molybdenum and tungsten [3]. Considering the first one, it has been often proposed in the open literature that the $\gamma^{\prime}$ growth negatively affects mechanical properties, since an easier plastic flow is usually observed with larger precipitates, favoring easier particle shearing or Orowan by-passing mechanisms [4, 5]. Characterizing the $\gamma^{\prime}$ growth kinetics and measuring their impact on the creep properties, is hence highly desirable.

The other possible side effect of long term thermal exposure is the nucleation of TCP phases. Very different kinds of TCP particles can be encountered in Ni-based superalloys, depending on their chemistry and crystallographic structure (e.g. $\mu, \mathrm{P}, \sigma$ or R phases) [3]. As an example, $\mu$ and $\mathrm{P}$ phases have a rhombohedral structure, while the $\mathrm{R}$ phase is orthorhombic and the $\sigma$ phase is tetragonal. In polycrystalline alloys prone to TCP precipitation, grain boundaries are usually observed as preferential nucleation sites [6]. Their morphology and crystallographic structure is even likely to evolve during overaging [3]. Since, it was already observed that René 88 DT alloy is prone to the precipitation of the $\mu$ phase for long-term aging (more precisely after 6300 hours at $760^{\circ} \mathrm{C}$ ), in addition to the precipitation of secondary carbides and $\mathrm{M}_{23} \mathrm{C}_{6}$ and borides $\mathrm{M}_{3} \mathrm{~B}_{2}$ [2], it is here anticipated that $\mathrm{R} 65$ will also be prone to the precipitation of such deleterious phases.

Up to now, the question of the impact of TCP phases precipitation on the mechanical properties is open to debate and no common agreement can be found in the open literature. Theses phases are known to be brittle and favor crack initiation in Ni-based single crystals [7]. In addition, they are known to induce a solid-solution depletion in refractory elements and to disturb the regularity of the $\gamma^{\prime}$ precipitation locally [7, 8]. In the Ni-based single crystal MC2 alloy, the precipitation of a $\mu$-phase was potentially responsible for the decrease of both the high temperature ductility and creep life if its volume content was over $1 \%[7,8]$. In the polycrystalline superalloy K446, the $\mu$ precipitation was found to be the first cause of the mechanical properties degradation, the impact of the $\gamma^{\prime}$ growth being less pronounced [9]. In contrast, the $\mu$-phase precipitation in K465 alloy did not impact the time to failure, and the decrease in creep properties with overaging was correlated to the growth of the $\gamma^{\prime}$ precipitation [10]. To the authors' best knowledge, no study succeeded in demonstrating a possible intrinsic impact of the TCP precipitation on the high temperature creep properties.

In this context, the present work aims at characterizing the impact of two long-term thermal exposures on the high temperature creep properties of R65. This article will detail a specific methodology to separate the contributions of $\gamma^{\prime}$ growth and of TCP precipitation on the creep properties. 


\section{Material and experimental procedures}

Material and heat treatments

The typical chemical composition of R65 C\&W superalloy is given in Table I.

Table I. Chemical composition of René 65 (major elements, weight pct)

\begin{tabular}{cccccccccc} 
& $\mathrm{Ni}$ & $\mathrm{Fe}$ & $\mathrm{Co}$ & $\mathrm{Cr}$ & $\mathrm{Mo}$ & $\mathrm{W}$ & $\mathrm{Al}$ & $\mathrm{Ti}$ & $\mathrm{Nb}$ \\
\hline René 65 & Base & 1.0 & 13.0 & 16.0 & 4.0 & 4.0 & 2.15 & 3.75 & 0.7 \\
\hline
\end{tabular}

One part of the samples was machined out from a fully heat-treated disk. The applied solution treatment (ST) was $4 \mathrm{~h}$ at $1080^{\circ} \mathrm{C}$ followed by an air quench, and by a subsequent aging heat treatment of 8 hours at $760^{\circ} \mathrm{C}$. In the rest of the article, this fully heat treated disk will be considered as the reference state. Samples were machined in two sections having undergone solution treatment cooling rates of either $60-70^{\circ} \mathrm{C} / \mathrm{min}$ or $130-200^{\circ} \mathrm{C} / \mathrm{min}$. In these two sections, the mean grain size is about $10 \mu \mathrm{m}$ (ASTM 10), with some tiny areas of very small grains whose average size is about $3-5 \mu \mathrm{m}$, as shown in Fig. 1. After such forging and heat treatment steps, the primary $\gamma^{\prime}$ area fraction is about $8-11 \%$ and no intermetallic phases were observed. These samples were either used for creep testing at $700^{\circ} \mathrm{C} / 800 \mathrm{MPa}$ or for analyzing the impact of overaging on the microstructure and mechanical properties. Indeed, microstructure evolutions during overaging was studied for thermal annealings in the $700^{\circ} \mathrm{C}-925^{\circ} \mathrm{C}$ temperature range and for durations up to 2000 hours while the impact of overaging on the mechanical properties was studied after thermal anneals of either 4000 hours at $700^{\circ} \mathrm{C}$ or 500 hours at $800^{\circ} \mathrm{C}$. These thermal anneals were performed on blanks prior to the final machining of creep samples to avoid any surface damage due to oxidation. The temperature control during thermal overagings was performed using a K-type thermocouple in the immediate vicinity of the samples and with a $+/-$ $2^{\circ} \mathrm{C}$ accuracy. Samples were air quenched after these long-term agings.

Another group of samples was machined from the same disk, but in the as-forged condition (i.e. without any solution and aging heat treatments). These samples (blocks of size 20 $\mathrm{mm}^{*} 15 \mathrm{~mm} * 10 \mathrm{~mm}$ ) were used to performed solution heat treatment with controlled cooling rates in the $10^{\circ} \mathrm{C} / \mathrm{min}-11650{ }^{\circ} \mathrm{C} / \mathrm{min}$. These heat treatments were performed to characterize the evolution of the secondary $\gamma^{\prime}$ size as a function of the cooling rate. Each sample was equipped with a S-type thermocouple spot welded on its surface to measure exactly the cooling rate during these heat treatment. Cooling rates were determined by measuring the slope between $1000^{\circ} \mathrm{C}$ and $800^{\circ} \mathrm{C}$, i.e. in the main secondary $\gamma^{\prime}$ precipitation domain. Below $700^{\circ} \mathrm{C}$, the microstructure hardly evolves. The air and oil quenches correspond to cooling rates of $450{ }^{\circ} \mathrm{C} / \mathrm{min}$ and $11650^{\circ} \mathrm{C} / \mathrm{min}$ respectively.

Since the main aim of this study is to analyze the impact of thermal overaging on creep properties by separating the effect of both the $\gamma^{\prime}$ growth and the (possible) nucleation of TCP phases, having the $\gamma^{\prime}$ diameter - ST cooling rate relationship is required. Indeed, it is possible to simulate a given overaging of several hundreds or thousands of hours at a given temperature in terms of $\gamma^{\prime}$ size by selecting the appropriate ST cooling rate, but without the precipitation of intermetallic phases. After having characterized the $\gamma^{\prime}$ size after thermal agings of $4000 \mathrm{~h} / 700^{\circ} \mathrm{C}$ 
and $500 \mathrm{~h} / 800^{\circ} \mathrm{C}$, controlled ST cooling rates (with thermocouples spot-welded on the surface) were chosen in the $10^{\circ} \mathrm{C} / \mathrm{min}-7200^{\circ} \mathrm{C} / \mathrm{min}$ and applied to creep samples $(\sim 60 \mathrm{~mm}$ in length and $\sim 14 \mathrm{~mm}$ in diameter) prior to final machining and mechanical polishing to avoid any surface damage.

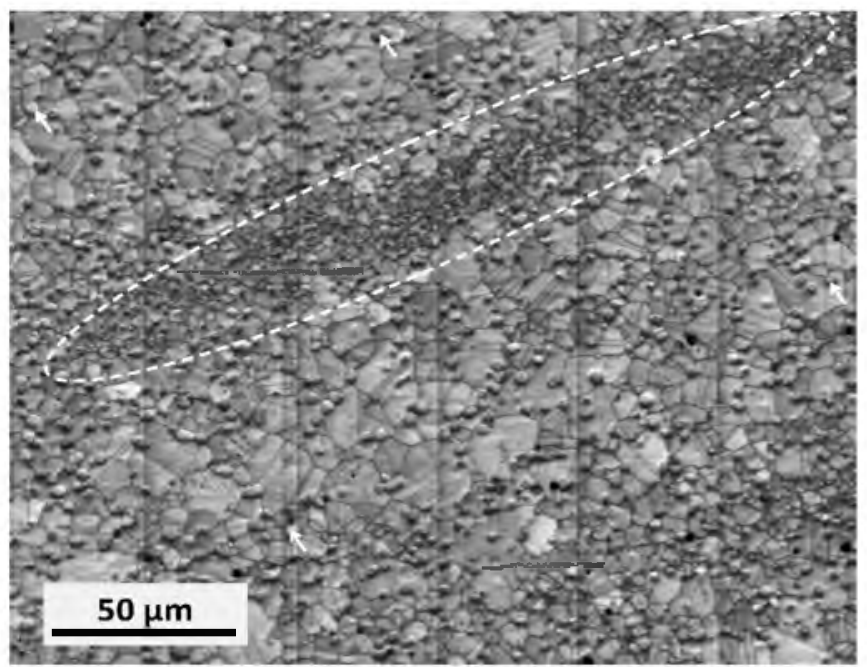

Figure 1. Granular structure of R65 alloy extracted from a given section of a sub-solvus heat treated forged disk and observed by EBSD (Image Quality contrast). White arrows are pointing out primary $\gamma^{\prime}$ particles located at grain boundaries and a very fine grain area is delineated by a white dotted ellipse.

\section{Creep testing}

All creep tests were performed at $700^{\circ} \mathrm{C} / 800 \mathrm{MPa}$ using a resistive air furnace. Sample temperature was controlled with a $+/-1{ }^{\circ} \mathrm{C}$ precision using a K-type thermocouple. The samples used were $56 \mathrm{~mm}$ in total length, $13 \mathrm{~mm}$ in gauge length and $\sim 4.3 \mathrm{~mm}$ in diameter. Prior to creep testing, the samples were mechanically polished using $\mathrm{SiC} 4000$ paper to remove scratches and layers affected by residual plastic deformation due to machining. During creep tests, the elongation was measured using a LVDT (Linear Variable Displacement Transducer), measuring the relative displacement.

\section{$\underline{\text { Microstructure characterizations }}$}

The $\gamma / \gamma^{\prime}$ microstructure and the possible precipitation of intermetallic phases at grain boundaries were characterized using the secondary electron mode (SEI) and the backscattered electron mode (BSE) of a JEOL JSM ${ }^{\mathrm{TM}} 7000 \mathrm{~F}$ field emission gun scanning electron microscope (FEG-SEM) operating in at $25 \mathrm{kV}$. Pictures were taken with magnifications ranging from 250 to $10,000 \mathrm{x}$ in BSE mode and to $100,000 \mathrm{x}$ in SEI mode. Observations of the $\gamma / \gamma^{\prime}$ microstructure were performed after mechanical polish to mirror finish (final polishing using a $1 \mu \mathrm{m}$ diamond) followed by chemical etch dissolving the $\gamma^{\prime}$ phase with $1 / 3 \mathrm{HNO}_{3}+2 / 3 \mathrm{HCl}$ (vol. part). Observations under BSE mode were performed after electrochemical polishing using perchloric acid (10 pct. vol.) in methanol.

The $\gamma^{\prime}$ particle size distributions as well as the intermetallic area fraction, were determined using the Visilog ${ }^{B}$ software and algorithms [11], based on at least 10 pictures taken in SEI mode for 
the $\gamma^{\prime}$ particles and in BSE mode for intermetallic phases. A minimum of $10000 \gamma^{\prime}$ particles were included in each distribution. After image analysis, each size distribution was characterized by a Log-Normal function, whose parameters were identified using Origin ${ }^{\mathbb{B}}$ Software. The $\gamma^{\prime}$ sizes provided are mean values as determined from this Log-Normal identification on each distribution.

Crystal phase identification was performed using the NanoMEGAS ASTAR orientation mapping unit combined with electron diffraction precession [12]. Diffraction patterns were recorded in a CM20-FEG transmission electron microscope (TEM) operated at $200 \mathrm{kV}$ using an angle of precession of about $1^{\circ}$. Each pattern is then indexed through comparison to pre-calculated kinematical diffraction templates of known phases. The index score which evaluates the degree of matching between electron diffraction and a particular template was used as a criteria for phase identification. For such analyses, TEM foils were prepared using low stress mechanical polishing to $\sim 30 \mu \mathrm{m}$ thickness, and a final thinning to electron transparency by ion milling.

\section{Experimental results}

\section{$\underline{\text { As-received and overaged microstructures }}$}

The intragranular $\gamma / \gamma^{\prime}$ precipitation in the two different areas of the forging studied in this article is presented in Fig. 2. A slightly coarser microstructure is observed in Fig. 2a compared to Fig $2 \mathrm{~b}$ due to a slower ST cooling rate $\left(\sim 70^{\circ} \mathrm{C} / \mathrm{min}\right)$ in comparison to a higher one $\left(\sim 170^{\circ} \mathrm{C} / \mathrm{min}\right)$ leading to the microstructure presented in Fig. $2 \mathrm{~b}$. These two areas will respectively be denoted as medium and fast ST cooling rate (MC and FC respectively) in the rest of the article. The difference in cooling rate between the two areas presented in Fig. 2 results from a difference in the forging thickness. The average $\gamma^{\prime}$ particle diameters are respectively $34 \mathrm{~nm}$ and $23.5 \mathrm{~nm}$ for the MC (Fig. 2a) and FC (Fig. 2b) solution treatments.

The microstructure obtained after the two studied overagings (i.e. $4000 \mathrm{~h} / 700^{\circ} \mathrm{C}$ and $500 \mathrm{~h} / 800^{\circ} \mathrm{C}$ ) are presented in Fig. 3. In this figure, overagings were performed on samples extracted from disk section having undergone a fast ST cooling rate. Comparing Fig. $3 \mathrm{a}$ and $3 \mathrm{~b}$, it is observed that the two thermal exposures are not equivalent since the resulting $\gamma^{\prime}$ size is smaller after $4000 \mathrm{~h}$ at $700^{\circ} \mathrm{C}$ compared to $500 \mathrm{~h}$ at $800^{\circ} \mathrm{C}$ (average $\gamma^{\prime}$ diameter of $31 \mathrm{~nm}$ and 70 nm respectively).

Grain boundary (GB) precipitation is also observed as white particles in BSE imaging after these two exposures (white arrows in Figs. 3c and 3d). These particles are mainly located at primary $\gamma^{\prime}$ particles-grain boundary junctions after overaging for $500 \mathrm{~h}$ at $800^{\circ} \mathrm{C} \mathrm{(Fig.} \mathrm{3c)} \mathrm{and} \mathrm{they} \mathrm{appear}$ coarser in comparison to the ones obtained after $4000 \mathrm{~h}$ at $700^{\circ} \mathrm{C}$ (Fig. 3d). After $4000 \mathrm{~h}$ at $700^{\circ} \mathrm{C}$, these particles nucleate along grain boundaries either in the form of discrete particles or in the form of a continuous film and without any preferential nucleation close to primary $\gamma^{\prime}$ precipitates. It should be mentioned here that EDS experiments performed under SEM indicated local enrichments in $\mathrm{Cr}$, Mo and $\mathrm{W}$ in these particles (not shown here), as usually observed for borides and TCP phases $[2,3]$. 


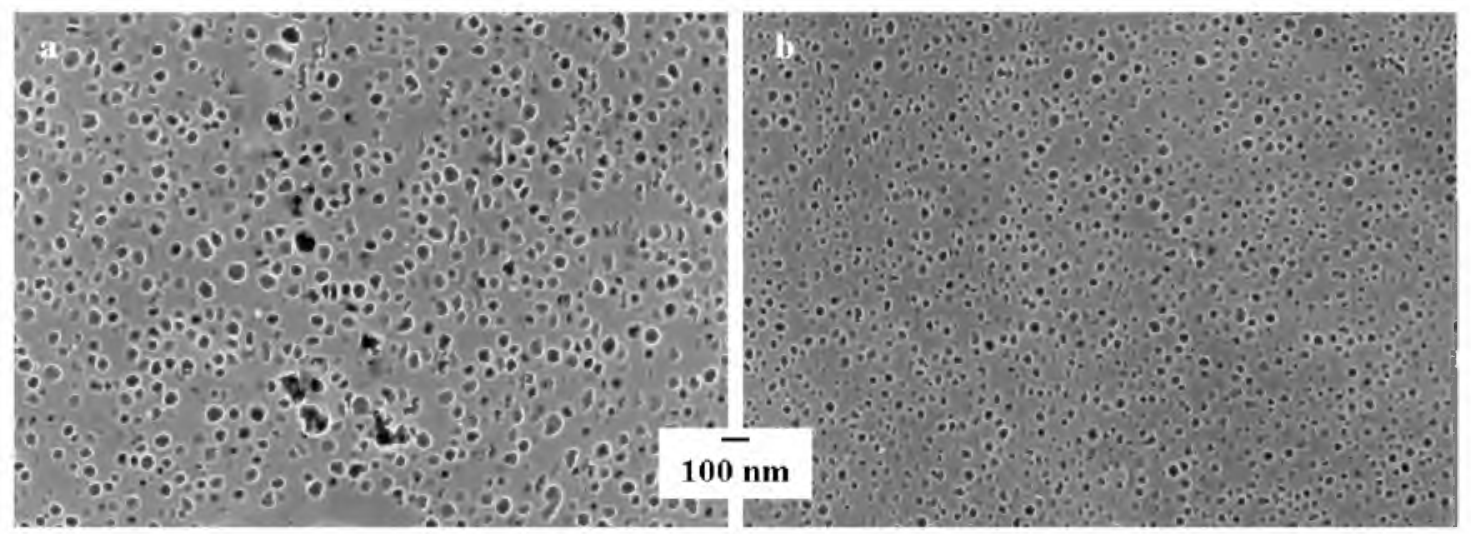

Figure 2. $\gamma / \gamma^{\prime}$ intragranular precipitation in the fully heat treated disk in areas having a medium (a) and a fast (b) ST cooling rate.
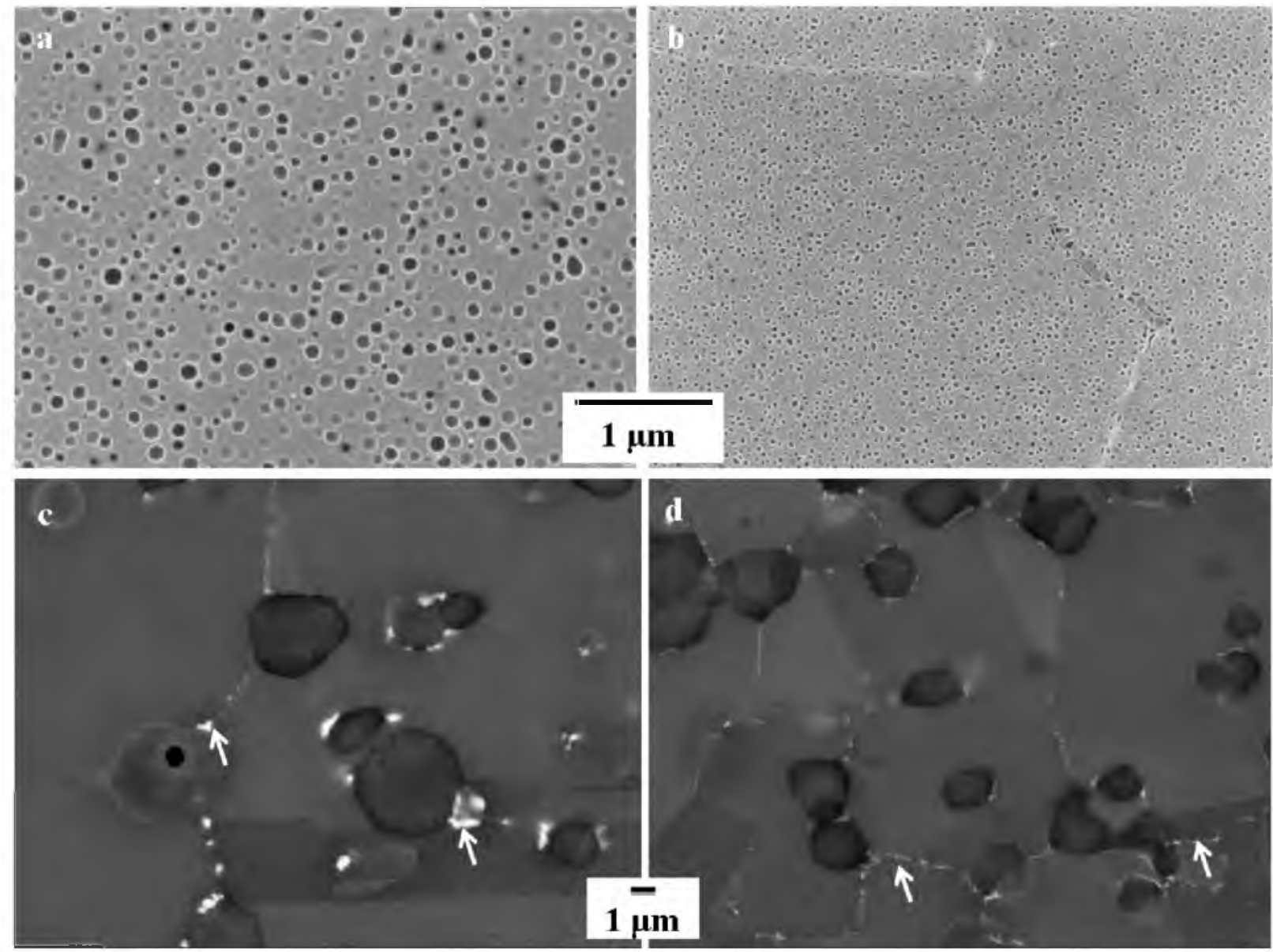

Figure 3. 25,000x SEI micrographs of $\gamma / \gamma^{\prime}$ intragranular precipitation $(a, b)$ and 5000x BSE micrographs of grain boundary precipitation highlighted by white arrows (c, d) after overaging for 500 hours at $800^{\circ} \mathrm{C}(\mathrm{a}, \mathrm{c})$ and 4000 hours at $700^{\circ} \mathrm{C}(\mathrm{b}, \mathrm{d})$.

To determine the exact crystalline structure of the observed GB boundary precipitation at $800^{\circ} \mathrm{C}$, a sample aged for 2000 hours at this temperature was analyzed by TEM. Only a small coarsening of GB particles and almost no difference in their volume fraction between samples aged for $500 \mathrm{~h}$ or $2000 \mathrm{~h}$ at this temperature was observed. It was hence decided to analyze a sample aged for $2000 \mathrm{~h}$ to ease the observation and area selection for diffraction under TEM. An example of these 
GB particles is given in the insert of Fig. 4. This blocky precipitate appears with strips extending throughout the entire particle. These strips, which correspond to stacking faults, are often encountered in TCP particles such as $\mathrm{P}, \sigma$ or $\mu$ phases [3]. Typical diffraction patterns obtained in different GB particles and for different diffraction conditions are shown in the left column of Fig. 4. They have been compared to typical diffraction patterns of $\mathrm{P}, \mu$ and $\sigma$ phases simulated by the ASTAR software from data extracted from the literature [3]. It is observed that the selected spots of the experimental diffraction patterns (second column from the left in Fig. 4) are really similar to $\mathrm{P}$ and $\mu$ phase, with a higher degree of confidence with the $\mu$ phase, especially in terms of lattice parameters. In addition, no correspondence with the diffraction patterns of borides $\left(\mathrm{M}_{3} \mathrm{~B}_{2}, \mathrm{M}_{5} \mathrm{~B}_{3}\right.$ and $\left.\mathrm{M}_{2} \mathrm{~B}\right)$ was founded. The $\mathrm{GB}$ boundary precipitation observed after long-term overagings at $800^{\circ} \mathrm{C}$ is hence $\mu$ phase. It should also be noted here that no exact identification of GB particles could have been performed after the $4000 \mathrm{~h} / 700^{\circ} \mathrm{C}$ overaging. This GB precipitation should be $\mathrm{M}_{3} \mathrm{~B}_{2}$ borides according to Wlodek et al. [2].

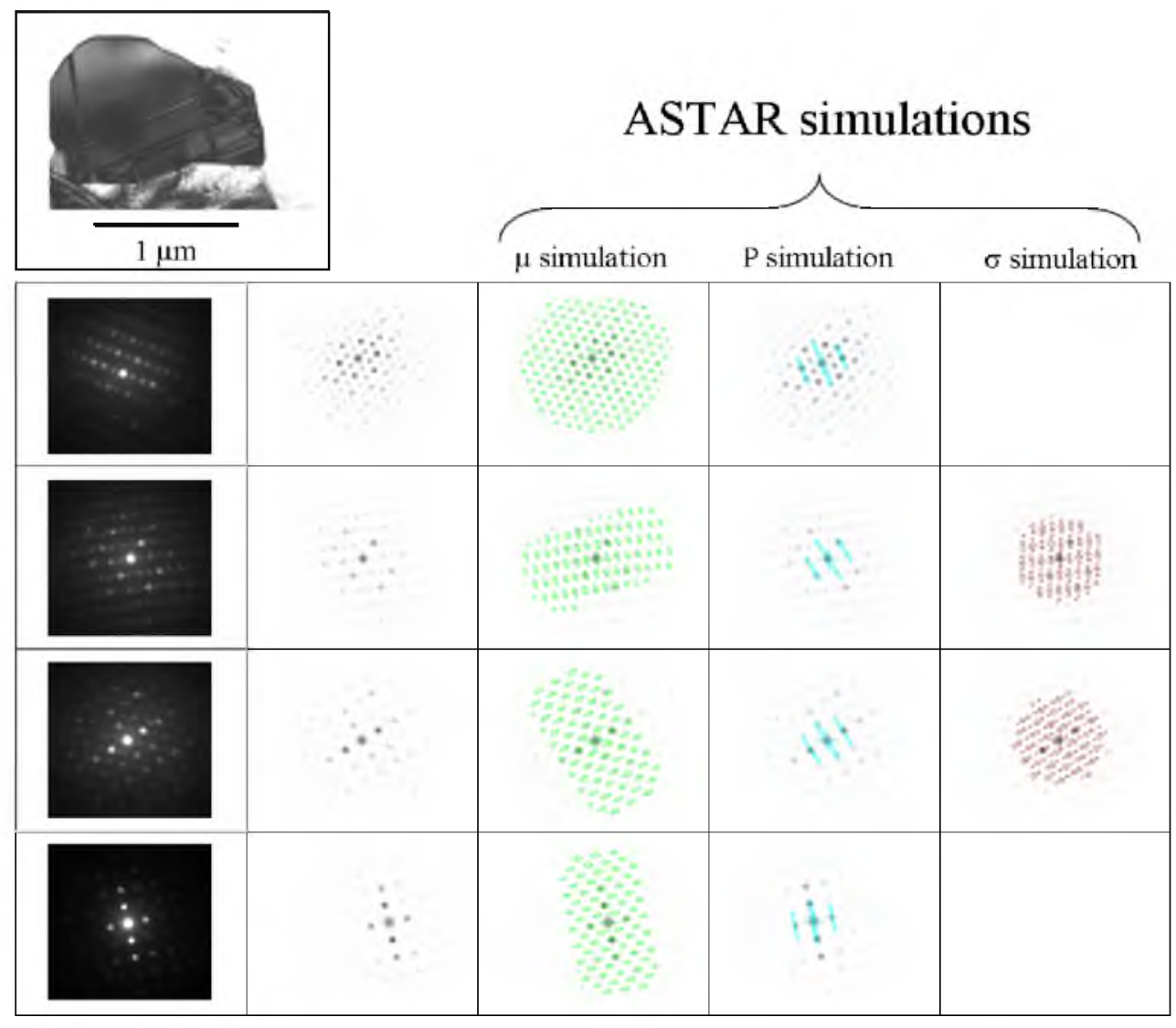

Figure 4. TEM diffraction patterns (left columns) obtained in a sample overaged for 2000 hours at $800^{\circ} \mathrm{C}$ and corresponding simulated diffraction patterns of the $\mu, P$ and $\sigma$ phases (right columns) using the ASTAR software. Note that a GB particle observed under TEM in bright contrast is shown in the insert.

\section{Intragranular $\gamma^{\prime}$ growth during overaging}

Overaging for up to 4000 hours in the $700^{\circ} \mathrm{C}-925^{\circ} \mathrm{C}$ temperature range were performed to analyze the intragranular $\gamma^{\prime}$ growth. Representative FEG-SEM pictures for samples aged at $750^{\circ} \mathrm{C}, 800^{\circ} \mathrm{C}, 850^{\circ} \mathrm{C}$, and $900^{\circ} \mathrm{C}$ for 100 hours are shown in Figure 5. $\gamma^{\prime}$ growth with increasing 
temperature results from a coalescence process of the precipitates, as highlighted by arrows in Fig. 5. It is also worth mentioning that $\gamma^{\prime}$ particles remain spherical even for the most severe overagings, both in terms of duration and temperature. This clearly indicates that $\gamma^{\prime}$ particles remain coherent with the $\gamma$ matrix, at least partially, within the investigated conditions [13].

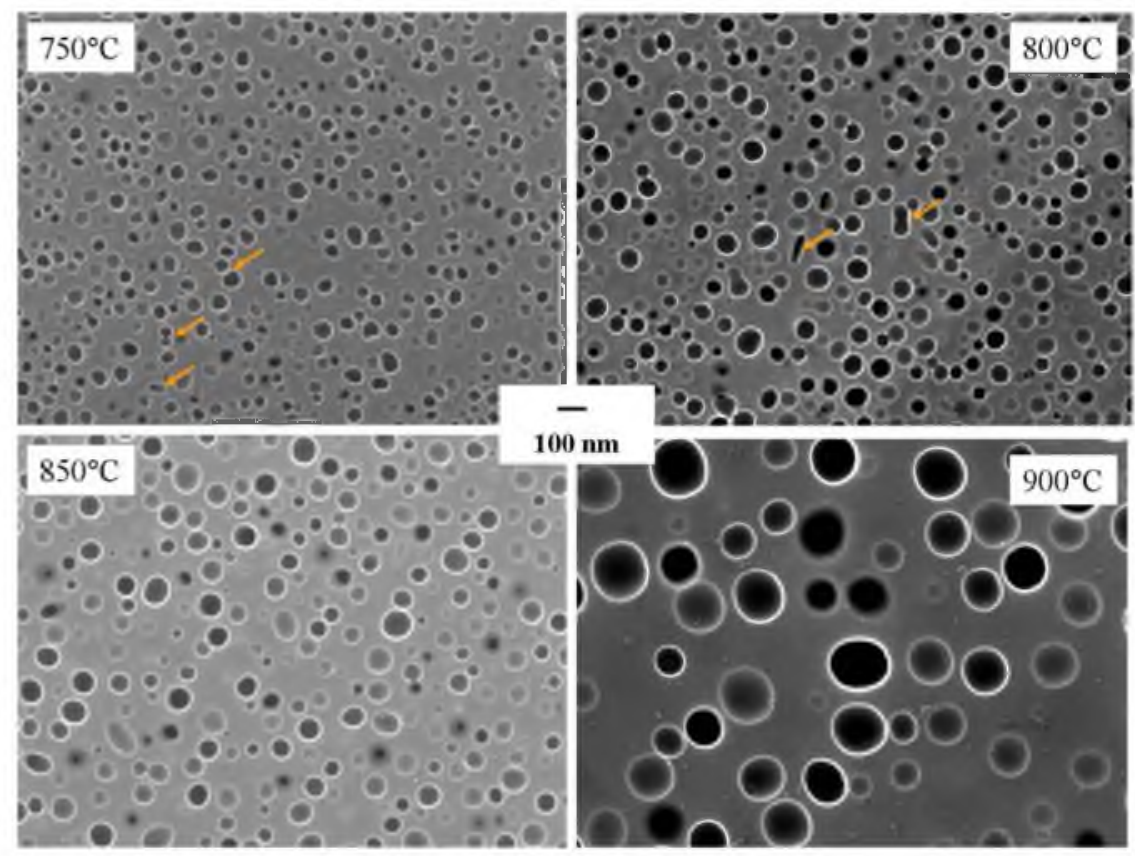

Figure 5. Intragranular $\gamma^{\prime}$ growth after a 100 hours aging in the $750^{\circ} \mathrm{C}-900^{\circ} \mathrm{C}$ range. Orange arrows highlight local coalescence events.

Since the $\gamma^{\prime}$ growth is a diffusion controlled process, it satisfies the Lifshitz-Slyozov-Wagner (LSW) theory where the mean radius $r$ of $\gamma^{\prime}$ particles satisfies the following relationship $[14,15]$ :

$$
r^{3}-r_{0}^{3}=K \times t
$$

In this equation, $r_{0}$ is initial mean radius of the particles and $\mathrm{K}$ is the coarsening rate. This coarsening rate $\mathrm{K}$ depends on the particles-matrix interfacial energy $\Gamma$, on the concentration of solute atoms in equilibrium with a particle of infinite radius $\mathrm{C}_{\mathrm{e}}$, on the molar volume of the precipitate $\mathrm{V}_{\mathrm{m}}$, on the absolute temperature $\mathrm{T}$ and on the diffusion coefficient of the solute atoms in the matrix $\mathrm{D}$ according to equation 2

$$
\mathrm{K}=\alpha \frac{\Gamma \mathrm{C}_{\mathrm{e}} \mathrm{V}_{\mathrm{m}}^{2}}{\mathrm{RT}} \mathrm{D}
$$

In this equation, $\mathrm{R}$ is the Boltzmann constant and $\alpha$ is parameter accounting for the particles' morphology. Since the diffusion coefficient $\mathrm{D}$ in Eq. 2 is defined as $\mathrm{D}=\mathrm{D}_{0} \exp \left(-\frac{\mathrm{Q}}{\mathrm{RT}}\right)$, Eq. 2 then rewrites:

$$
\mathrm{K}=\alpha \frac{\Gamma \mathrm{C}_{\mathrm{e}} \mathrm{V}_{\mathrm{m}}^{2} \mathrm{D}_{0}}{\mathrm{RT}} \exp \left(-\frac{\mathrm{Q}}{\mathrm{RT}}\right)
$$

In this equation, $\mathrm{D}_{0}$ is a constant. Assuming that the concentration $\mathrm{C}_{\mathrm{e}}$ is a constant over the temperature range considered in this study, the activation energy $Q$ for the coarsening of 
secondary $\gamma^{\prime}$ particles in R65 alloy can easily be determined from the slope of a $\ln \left(\mathrm{K}^{*} \mathrm{~T}\right)$ versus 1/T plot. Using the slopes of the $\gamma^{\prime}$ growth kinetics shown in Fig. 6a (i.e. $r^{3}-r_{0}{ }^{3}$ vs time plots), an apparent activation energy $\mathrm{Q}=358 \mathrm{~kJ} \cdot \mathrm{mol}^{-1}$ has been measured (Fig. $6 \mathrm{~b}$ ).
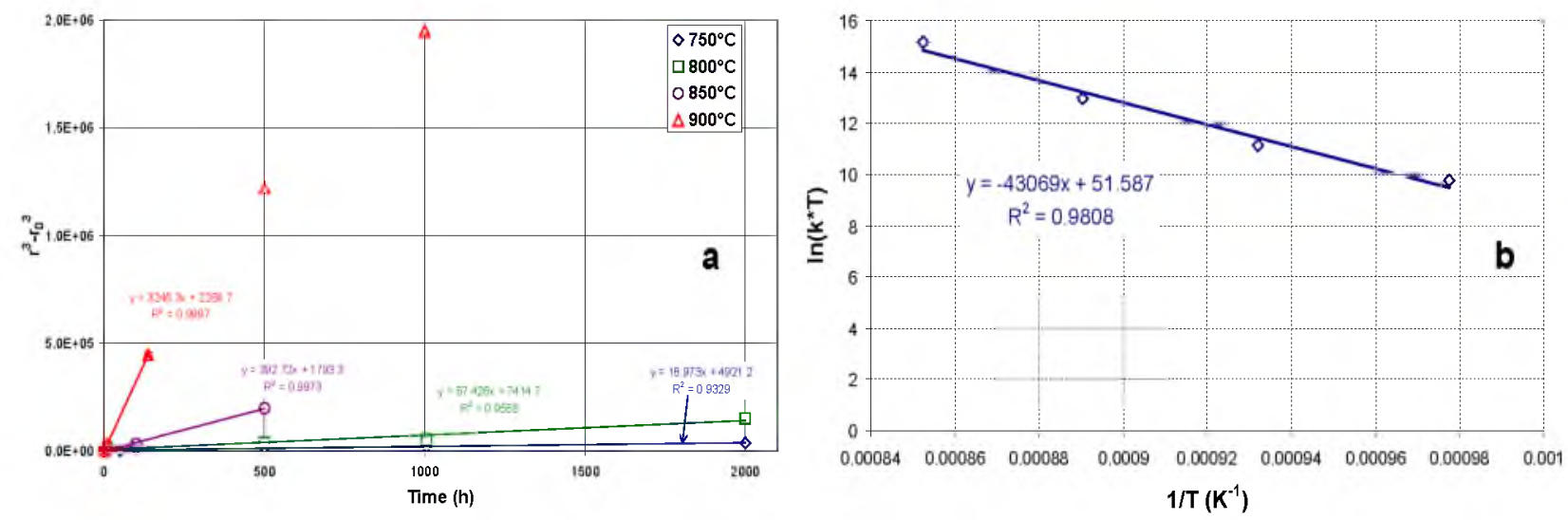

Figure 6. LSW plots at $750^{\circ} \mathrm{C}, 800^{\circ} \mathrm{C}, 850^{\circ} \mathrm{C}$ and $900^{\circ} \mathrm{C}$ (a) and resulting determination of the activation energy (b) for the intragranular $\gamma^{\prime}$ growth.

From Fig. 6a, it is observed that the LSW theory is valid within the investigated duration at $750^{\circ} \mathrm{C}, 800^{\circ} \mathrm{C}$ and $850^{\circ} \mathrm{C}$. However, at $900^{\circ} \mathrm{C}$, the LSW model is no longer valid after $\sim 100 \mathrm{~h}$. This deviation from the LSW theory may result from a $\gamma^{\prime}$ solute starving or from a mean free path for diffusion that is changing, leading to a different apparent growth regime. The activation energy here obtained for $\mathrm{R} 65\left(\mathrm{Q}=358 \mathrm{~kJ}^{\mathrm{mol}}{ }^{-1}\right)$ is in quite good agreement with other forged $\mathrm{Ni}$-based superalloys. Indeed, as an example, the activation energy reaches $335 \pm 6 \mathrm{~kJ} / \mathrm{mol}$ for the growth of tertiary $\gamma^{\prime}$ in N18 alloy [16].

Impact of the cooling rate from solution heat treatment on $\gamma^{\prime}$ precipitation

The evolution of intragranular $\gamma^{\prime}$ precipitation as a function of ST cooling rate is shown in Fig. 7. A progressive decrease of the $\gamma^{\prime}$ size is observed with increasing ST cooling rate. In addition, a loss of coherency for the slowest ST cooling rate with $\gamma^{\prime}$ particles exhibiting a butterfly morphology (Fig. 7a) is observed. These results are in good agreement with Steuer et al. who studied the impact of the ST cooling rate on the $\gamma^{\prime}$ precipitation and creep properties of AM3 Nibased single crystal superalloy [17].

Since the $\gamma^{\prime}$ growth during continuous ST cooling is a diffusion controlled process, the $\gamma^{\prime}$ diameter $\phi_{\gamma^{\prime}}$ usually exhibits a power law dependence to cooling rate $\dot{\mathrm{T}}_{\mathrm{C}}$ according to Eq. 4:

$$
\phi_{\gamma^{\prime}}=\alpha\left(\dot{\mathrm{T}}_{\mathrm{C}}\right)^{-\beta}
$$

In this equation, $\alpha$ and $\beta$ are material parameters depending on the content of $\gamma^{\prime}$-elements in solution (i.e. at the ST temperature). The evolution of the $\gamma^{\prime}$ diameter as a function of cooling rate is shown in Fig. 8 and is in good agreement with power law dependence. The power law parameters $(\alpha ; \beta)$ determined for this subsolvus heat treated R65 alloy are $(364.74 ; 0.3977)$. Fig. 8 also compares R65 to data generated by J.R. Vaunois and al. for C\&W Udimet 720Li (U720Li) alloy also solution treated at $1080^{\circ} \mathrm{C}$ for 4 hours [11]. It is observed that the $\gamma^{\prime}$ particles in R65 
are smaller for given ST cooling rate. This probably results from the higher $\gamma^{\prime}$ content in U720Li in comparison to R65.

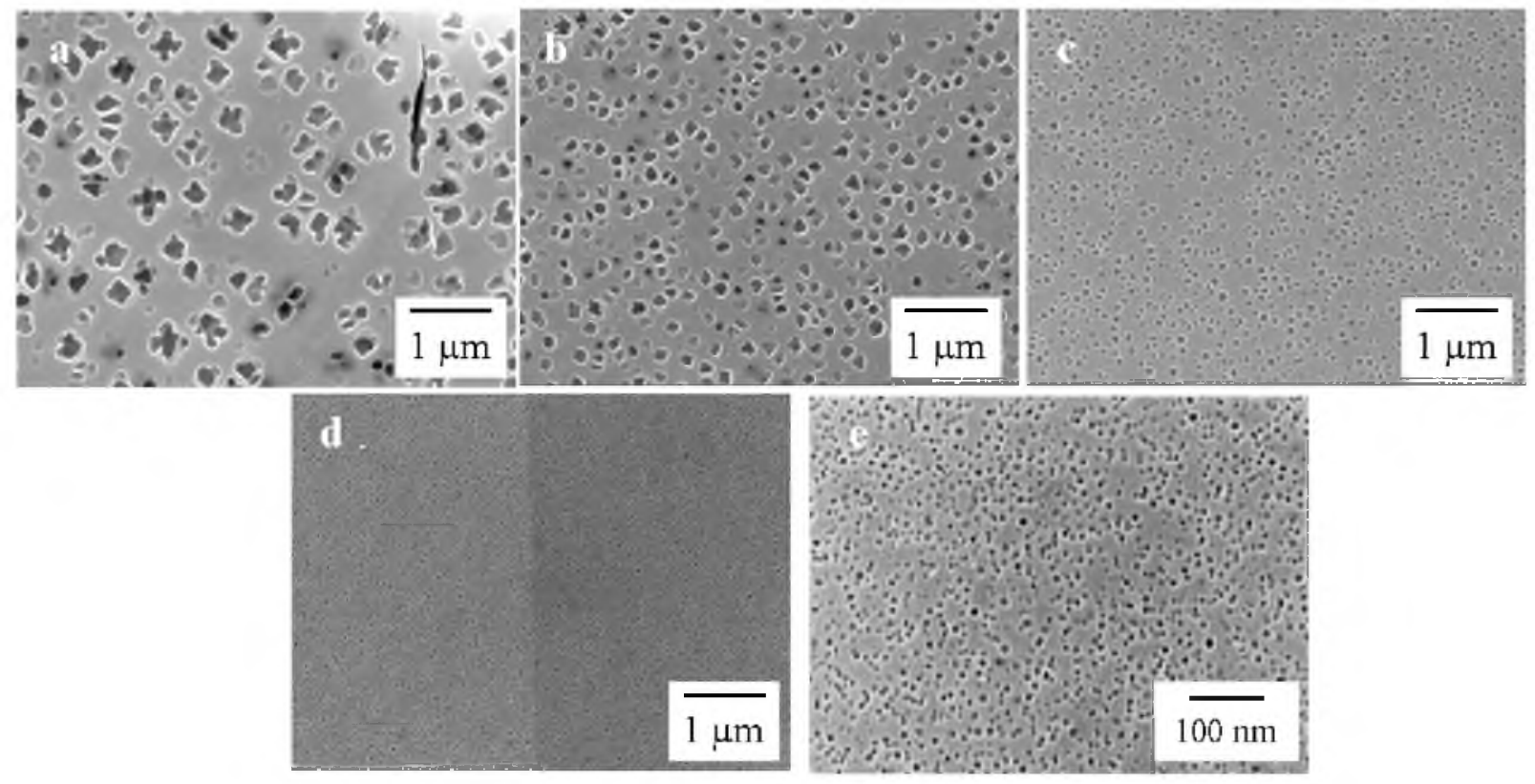

Figure 7. Intragranular $\gamma^{\prime}$ precipitation observed after a $4 \mathrm{~h} / 1080^{\circ} \mathrm{C} \mathrm{ST}$ and cooling rates of $10^{\circ} \mathrm{C} / \mathrm{min}(\mathrm{a}), 37^{\circ} \mathrm{C} / \mathrm{min}(\mathrm{b}), 108^{\circ} \mathrm{C} / \mathrm{min}$ (c), $450^{\circ} \mathrm{C} / \mathrm{min}$ (d) and $\sim 11650^{\circ} \mathrm{C} / \mathrm{min}$ (e).

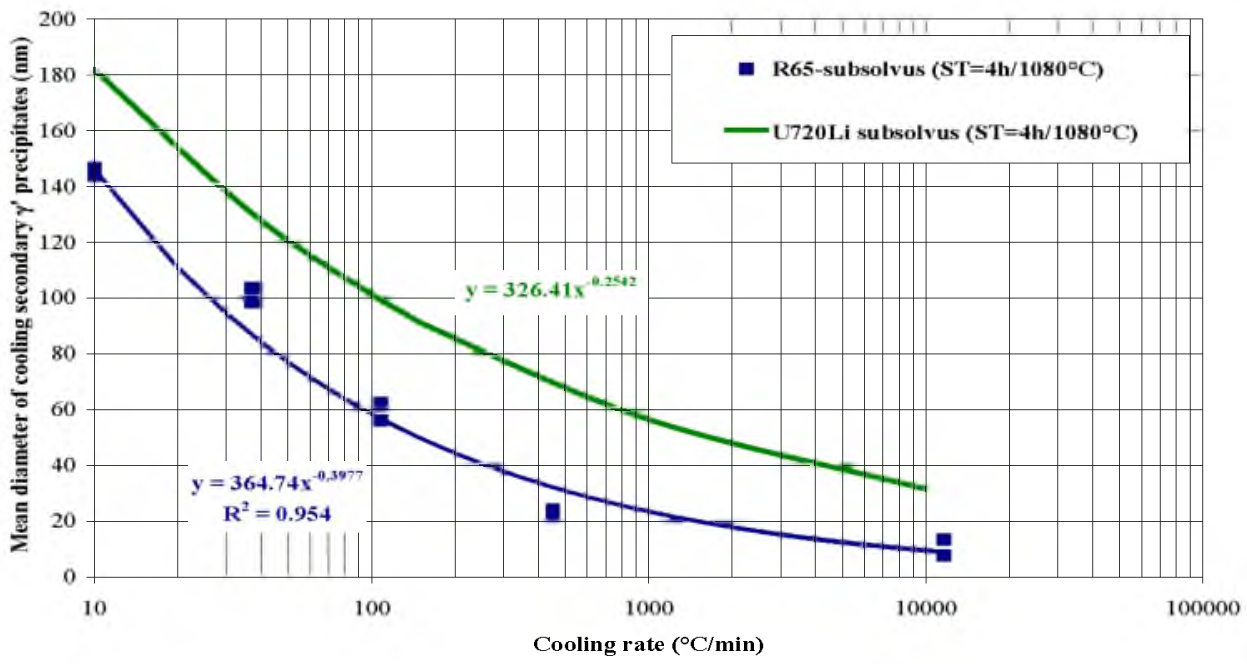

Figure 8. $\gamma^{\prime}$ size evolution as a function of the ST cooling rate for R65 (present study) and for a subsolvus C\&W Udimet 720Li alloy [11]

\section{Impact of overaging on creep properties}

The creep properties of $\mathrm{R} 65$ alloy at $700^{\circ} \mathrm{C} / 800 \mathrm{MPa}$ in the as heat-treated state in the $\mathrm{MC}$ and $\mathrm{FC}$ areas of the studied disk and after the two overaging conditions are shown in Fig. 9. As a first result, creep properties in disk areas rapidly cooled (FC) are better than medium ST cooling rate (MC). The creep life of FC is nearly twice the MC sample. 


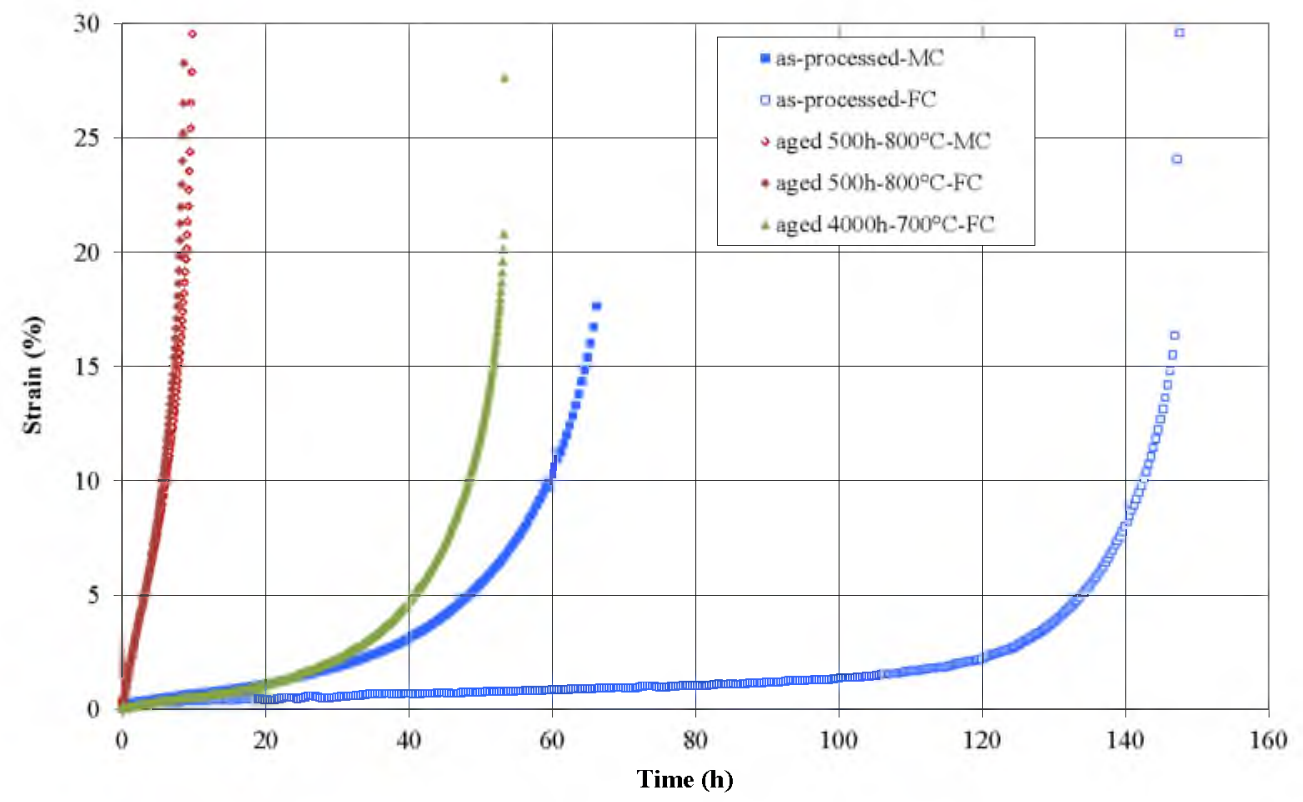

Figure 9. Creep properties of $\mathrm{R} 65$ alloy at $700^{\circ} \mathrm{C} / 800 \mathrm{MPa}$ after thermal exposures of $4000 \mathrm{~h}$ at $700^{\circ} \mathrm{C}$ and $500 \mathrm{~h}$ at $800^{\circ} \mathrm{C}$ compared to the as-processed alloy in the $\mathrm{MC}$ and $\mathrm{FC}$ areas.

Considering the impact of overaging at $800^{\circ} \mathrm{C}$ for 500 hours, the creep life is decreased by a factor over $15 \mathrm{x}$ compared to the longest creep life obtained for the as-processed sample rapidly cooled. The initial differences of MC and FC creep behavior are erased after such a long-term thermal exposure. The overaging performed at $700^{\circ} \mathrm{C}$ for $4000 \mathrm{~h}$ also induces a decrease of the creep properties compared to its unexposed counterpart. Indeed, the creep life after this last thermal exposure is decrease by a factor over $2 \mathrm{x}$ compared to the as-processed FC sample. Despite this degradation, the creep properties (creep strain rate and time to failure) are comparable to the as-processed sample machined in the MC area without a long-term thermal aging prior to creep test.

From these results and microstructure characterizations presented in Figs. 2 and 3, the samples perform according to the size of the intragranular $\gamma^{\prime}$ precipitation. However, a reliable evaluation of the creep performances under these conditions without the precipitation of $\mu$ phase is required, and presented subsequently.

\section{Creep properties after various ST cooling rates.}

The creep properties at $700^{\circ} \mathrm{C} / 800 \mathrm{MPa}$ after different ST cooling rates are presented in Fig. 10 . A slower stationary creep rate is obtained by increasing the ST cooling rate and, as expected under a Monkman-Grant assumption, a longer time to failure. A decrease of the strain to failure with an increased ST cooling rate is also observed in this figure. 


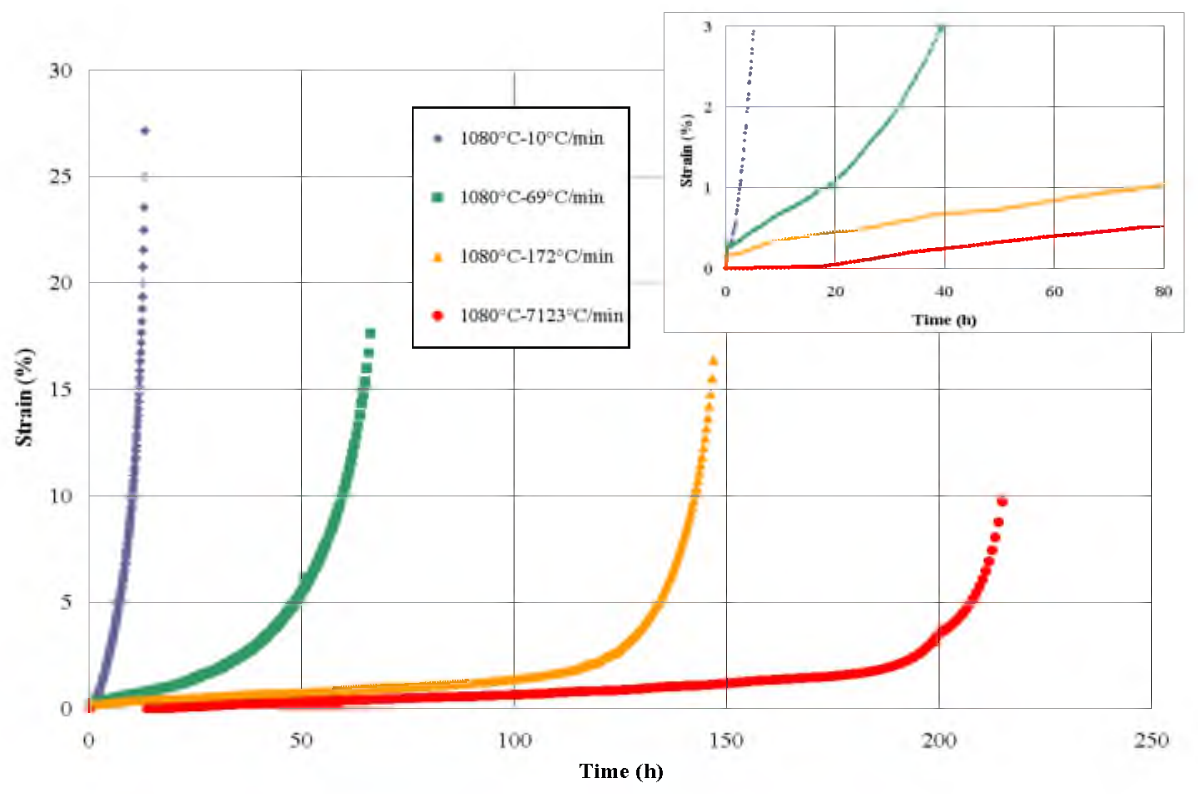

Figure 10. Creep properties of $\mathrm{R} 65$ alloy at $700^{\circ} \mathrm{C} / 800 \mathrm{MPa}$ with different ST cooling rates. A magnification of the first hours of creep is provided in the insert.

These results are again in good agreement with the results of Steuer et al. for a first generation Ni-based single crystal creep tested at $850^{\circ} \mathrm{C}$ [17], and also with those of Bhowal et al. for the PM metallurgy René 95 alloy creep tested at $650^{\circ} \mathrm{C}$ [5]. It is also interesting to notice that the sample cooled at $10^{\circ} \mathrm{C} / \mathrm{min}$ directly enters in the tertiary creep stages while the sample cooled at $7123^{\circ} \mathrm{C} / \mathrm{min}$ exhibits an incubation period of $\sim 15-20$ hours during which the creep strain rate is almost zero. This incubation period is typical of a very fine intragranular $\gamma^{\prime}$ precipitation which leads to a very high Orowan stress required for dislocation bowing in the $\gamma$ matrix between $\gamma^{\prime}$ particles. Indeed, the $\gamma^{\prime}$ size is $\sim 11 \mathrm{~nm}$ after such cooling (Fig. 8) and the material may only start to creep when the growth of $\gamma^{\prime}$ particles during the creep test will be sufficient to allow $\gamma^{\prime}$ dislocation by-passing.

In summary, the monotonic dependence of the creep properties at $700^{\circ} \mathrm{C} / 800 \mathrm{MPa}$ to the intragranular $\gamma$ size clearly indicates that the main creep controlling deformation mechanism under such conditions is dislocation glide in the matrix and Orowan by-passing [5].

\section{Discussion}

The creep properties at $700^{\circ} \mathrm{C} / 800 \mathrm{MPa}$ of $\mathrm{R} 65$ alloy have been characterized with two ST cooling rates (i.e. without any GB precipitation) and after overaging at $700^{\circ} \mathrm{C}$ and $800^{\circ} \mathrm{C}$. With these results, it is possible to analyze objectively the creep properties by plotting both the evolution of the of the stationary creep strain rate (Fig. 11a) and of the creep life (Fig. 11b) as a function of the intragranular $\gamma^{\prime}$ size. By using such a plot, if the $\mu$ phase present at grain boundaries after overaging at $800^{\circ} \mathrm{C}$ has an intrinsic impact on the creep properties, a deviation of the creep life and/or of the creep strain rate from the general trend linking these two creep characteristics to the intragranular $\gamma^{\prime}$ size is observed. 
This deviation from the general trend linking the creep strain rate to the $\gamma^{\prime}$ particle size is observed in Fig. 11a where creep strain rate is nearly one decade faster than what it would have been without TCP GB precipitation, leading to a $3 x$ reduction in creep life.
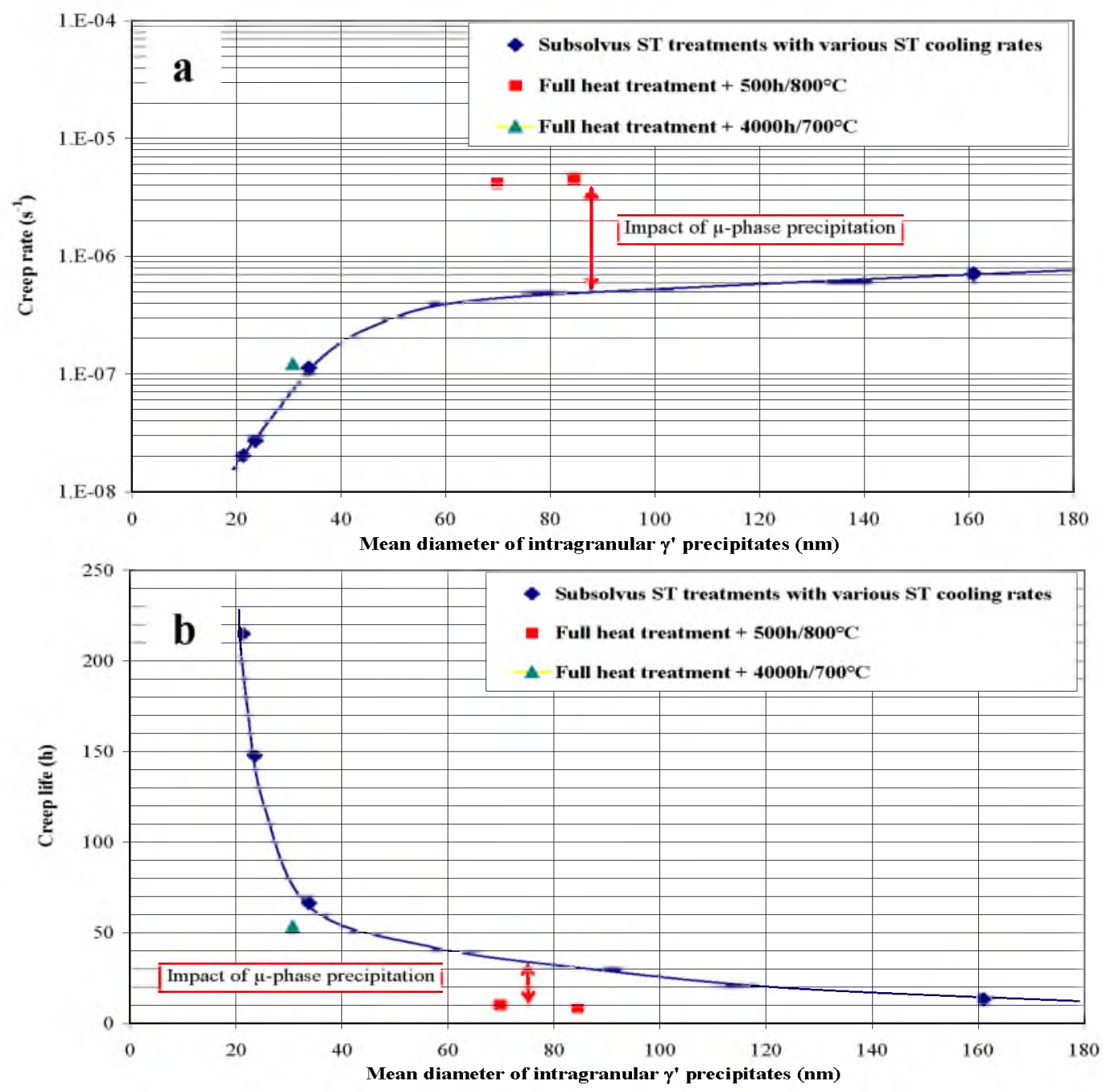

Figure 11. Impact of $\mu$-phase on creep rate (a) and on creep life (b) of R65 alloy at $700^{\circ} \mathrm{C} / 800$ $\mathrm{MPa}$

A direct comparison with experimental results having only a coarsened intragranular $\gamma^{\prime}$ precipitation whose size is $\sim 70-85 \mathrm{~nm}$ but without $\mu$ precipitation would have been better for a direct evaluation of the impact of the GB TCP precipitation on the creep properties in Fig. 11. This work is currently in progress and the ST cooling chosen to achieve a $\gamma$ ' size comparable to a 500 hours overaging at $800^{\circ} \mathrm{C}$ has been determined by using Eqs. 1 and 4 . We are however very confident in the obtained trends and on the observed detrimental impact of $\mu$ on the creep properties of $\mathrm{R} 65$ at $700^{\circ} \mathrm{C}$. The detrimental impact does not result from a drop of the creep ductility as may have been expected, since preferential creep cavitation was not observed close to TCP phases. This drop in creep properties with the precipitation of GB $\mu$ phase is probably linked to a solid solution depletion in refractory elements, and to a $\gamma$ ' depleted layer close to grain boundaries $[2,8]$ since the creep behavior is impacted in the secondary creep stage and not only during tertiary creep stage. 
Considering the impact of the 4000 hours overaging at $700^{\circ} \mathrm{C}$, both the secondary creep strain rate and the creep life are almost identical to the sample having the same $\gamma$ ' size, but without GB precipitation (Fig. 11). Consequently, the creep resistance decrease after overaging solely results from the $\gamma^{\prime}$ growth and not from the GB precipitation. This could be explained by a different kind of GB precipitation (probably $\mathrm{M}_{3} \mathrm{~B}_{2}$ borides [2]) or by a GB precipitation volume fraction low enough to hardly affect the creep properties [7].

The focus of this study was to evaluate the effect of overaging on creep properties of the R65 alloy. This study will be extended to fatigue and dwell-fatigue properties where impact of longterm thermal exposure on these mechanical properties is expected.

\section{Conclusions}

The impact of thermal overaging on creep properties at $700^{\circ} \mathrm{C} / 800 \mathrm{MPa}$ of René 65 alloy has been studied. All experiments were performed using samples subsolvus heat treated to a fine average grain size $(\sim 10 \mu \mathrm{m})$. Methodology has been proposed to objectively analyze the impact of long-term thermal exposures on the creep properties when their consequences are both the $\gamma^{\prime}$ growth and the nucleation of deleterious TCP phases. This methodology consists of comparing the creep properties of overaged samples (i.e. having both a coarsened $\gamma^{\prime}$ precipitation and grainboundary TCP particles) to samples solution treated with controlled cooling rates to achieve a similar coarsened $\gamma^{\prime}$ microstructures without TCP precipitation.

By using this new methodology, it has been shown that the faster the ST cooling rate, the finer the intragranular $\gamma^{\prime}$ precipitation and the better the creep properties. Moreover, the decrease in creep properties after a 4000 hours thermal exposure at $700^{\circ} \mathrm{C}$ only results from intragranular $\gamma^{\prime}$ growth. In contrast, the degradation in creep properties after a 500 hours thermal exposure at $800^{\circ} \mathrm{C}$ results from both the $\gamma^{\prime}$ growth and from the precipitation of GB $\mu$ particles. It is here shown unambiguously a detrimental impact of $\mu$ phase to the creep properties at $700^{\circ} \mathrm{C}$.

\section{Acknowledgements}

Aude Laurence is grateful to Snecma - SAFRAN group for her Ph.D grant and to Florence Hamon (Institut Pprime) for her help in creep tests. Jonathan Cormier and Patrick Villechaise are grateful to Snecma - SAFRAN group for funding this study and for collaboration on Ni-based superalloys research activities for over 10 years.

\section{References}

1. L. Mataveli Suave, J. Cormier et al., "Microstructural evolutions during thermal aging of alloy 625: impact of temperature and forming process", Metallurgical and Materials Transactions A, 45 (2014), 2963-2982

2. S.T. Wlodek, M. Kelly et al., "The structure of the Rene88DT", (Paper presented at Superalloys 1996, Seven Springs, Champion, PA, USA, 1996), 129-136 
3. C.M.F. Rae, R.C. Reed, "The precipitation of topologically closed-packed phases in rheniumcontaining superalloys", Acta Materialia, 49 (2001), 4113-4125

4. T. Billot, « Comportement et endommagement en fatigue et fatigue-fluage à haute température de différents états microstructuraux du superalliage base-nickel Udimet 720 », (PhD. Thesis, ENSMA, 2010)

5. P.R. Bhowal et al., "Effects of cooling rate and $\gamma$ ' morphology on creep and stress-rupture properties of a powder metallurgy superalloy", Metallurgical and Materials Transactions A, 21 (1990), 1709-1717

6. R.C. Reed et al., "Characterization and modeling of the precipitation of the sigma phase in Udimet 720 and Udimet 720Li", Metallurgical and Materials Transactions A, 30 (1999), 521533

7. S. Simonetti and P. Caron, "Role and behavior of $\mu$ phase during deformation of a nickelbased single crystal superalloy", Materials Science and Engineering, A 254 (1998), 1-12

8. J-B. le Graverend, J. Cormier et al., "Numerical simulation of $\gamma / \gamma$ ' microstructural evolutions induced by TCP-phase in the MC2 nickel base single crystal superalloy", Materials Science and Engineering, A 528 (2011), 2620-2634

9. X.Z. Quin et al. "Long-term thermal exposure responses of the microstructure and properties of a cast Ni-base superalloy", Materials Science and Engineering, A 543 (2012), 121-128

10. J.X. Yang, Q. Zheng et al., "Formation of $\mu$ phase during thermal exposure and its effect on the properties of K465 superalloy", Scripta Materialia, 55 (2006) 331-334

11. J-R Vaunois, J. Cormier et al., (Paper presented at 7th International Symposium on Superalloy 718 and Derivatives, Pittsburgh, PA, USA, 2010), 199-213

12. E.F. Rauch, M. Véron, et al., "Automatic crystal orientation and phase mapping in TEM by precession diffraction", Microscopy and Analysis Nanotechnology Supplement, November (2008), S5-S8

13. D.M. Collins, L. Yan et al., « Lattice misfit during ageing of polycristakkine nickel-base superalloy", Acta Materialia, 61 (2013), 7791-7804

14. I.M. Lifshitz and V.V. Slyozov, Journal of Physical Chemistry solids, 19 (1961), 35-50.

15. C. Wagner, Zeitschrift fuir Elektrochemie, 65 (7/8) (1961), 581-591.

16. B. Flageolet, P. Villechaise et al., "Ageing characterization of the powder metallurgy superalloy N18", (Paper presented at Superalloys 2004, Seven Springs, Champion, PA, USA, 2004), 371-379. 
17. S. Steuer, Z. Hervier et al., "Creep behavior under isothermal and non-isothermal conditions of AM3 single crystal superalloy for different solutioning cooling rates", Materials Science and Engineering $A$, 601 (2014), 145-152 